\title{
A ADOLESCÊNCIA SOB A ÓTICA PSICANALITICA: sobre o luto adolescente e de seus pais
}

DOI: $10.22289 / 2446-922 X . V 2 N 2 A 8$

\author{
Laydiane Pereira de Matos \\ Karla Priscilla Lemgruber ${ }^{1}$
}

\section{RESUMO}

O seguinte trabalho tem por objetivo discorrer sob o enfoque psicanalítico alguns aspectos psíquicos que envolvem a complexa fase da vida intitulada adolescência, enfatizando os processos de luto pelos quais pais e filhos têm de passar. Para isso, foi realizada uma pesquisa exploratória de levantamento bibliográfico através de bases de dados como Scielo e Pepsic, além de consulta em obras clássicas de Psicanálise citando teóricos como Freud, Anna Freud, Erik Erikson, Aberastury e Knobel, dentre outros. O estudo mostrou que o pensar adolescente é repleto de características peculiares e distintas que justificam suas atitudes muitas vezes tidas como problemáticas. A maior parte dessas características está ligada ao processo de desprendimento necessário que o jovem tem de realizar em relação as figuras paternas. São os pais quem são os responsáveis por fornecerem continente, base e sustentação para que seus filhos adolescentes atravessem esse conturbado período de mudanças. Atitudes que constroem tal base devem iniciar-se logo nos primeiros anos de criação desses filhos, através da boa comunicação, diálogo, e uma certa dose de liberdade; e requer que esse cuidado se prolongue por toda a vida, exigindo que os pais permitam-se conhecer-se, repensar suas vivencias passadas enquanto adolescentes, e assumir verdades que nem sempre Ihes agradam, para que venham - assim - situarem-se no momento presente e ressignificarem seus lugares enquanto pais e sujeitos.

Palavras-Chave: Adolescer, Figuras paternas, Psicanálise.

\section{ABSTRACT}

The objective of this paper is to talk, under a psychoanalytic optic, about some psychic aspects involving the complex phase of life called adolescence, highlighting the grieving process by which parents and children need to experience. For that matter, an exploratory search of literature was conducted. The study showed that adolescent thinking is filled with unique and distinct features that justify their attitudes often seen as problematic. Most of these features are linked to the necessary detachment process that the young have to perform in relation to the father figures. Parents are the responsible for providing the foundation for their children to go through this confusing period of change. Attitudes that build such a base must be initiated in the first years of creation of these children, with good communication, dialogue, and a certain

\footnotetext{
${ }^{1}$ Endereço eletrônico de contato: karlalemgruber@hotmail.com
}

Recebido em 16/12/2016. Aprovado pelo Conselho Editorial e aceito para publicação em 16/01/2016.

Rev. Psicol Saúde e Debate. Jan., 2017:2(2):124-145. 
amount of freedom; and it is necessary that this care extends throughout life, demanding parents to let be known, rethink their past livings as adolescents, and admit truths not always pleasing, so that then can be placed in the present moment and find their place as parents and subjects.

Keywords: Adolesce, Father figures, Psychoanalysis.

\section{INTRODUÇÃO}

Ao longo dos quase cinco anos do curso de psicologia pude vivenciar algumas experiências acadêmicas às quais observei dificuldades, nos quesitos teórico e prático, por parte de pais e educadores na maneira de lidar com adolescentes. No atual cenário político e social, com os frequentes debates de proposta de redução da maioridade penal, percebo o quão equivocados são os julgamentos acerca da tolerância com as transgressões desses jovens - muitas vezes ignorando-se as particularidades próprias dessa fase da vida. Ouço declarações absurdas que ferem o que é previsto pelo Estatuto da Criança e do Adolescente (ECA), equiparando jovens e adultos e procurando responsabilizá-los com a mesma rigidez de punições. Assim, a escolha pessoal desse tema para o presente trabalho foi baseada em um misto de estudos e aprendizados em psicologia aliados às minhas próprias experiências emocionais adolescentes. Juntas, essas influências acabaram por me instigar à pesquisa a respeito da adolescência e seus caminhos psíquicos.

A adolescência - enquanto fase da vida - pode ser tomada como um grupo de fenômenos que eclodem num dado momento, e que tem um processo e um desenvolvimento até o seu desaparecer, para dar lugar a comportamentos e fenômenos característicos da idade adulta. ${ }^{(1)}$ Ela corresponde a um período de descoberta dos próprios limites, de questionamento dos valores e normas familiares, bem como uma intensa adesão aos valores e normas de grupos e amigos. É um tempo de rupturas e aprendizados, uma etapa caracterizada pela necessidade de integração social, busca de autoafirmação e independência individual pela definição da identidade sexual. ${ }^{(2)}$ Sua essência é totalmente diferente das outras fases que permeiam o desenvolvimento humano: nela, o adolescente se recolhe num casulo como sendo uma crisálida em absoluta transformação, diferentemente da lagarta da infância e da borboleta da vida adulta. ${ }^{(2)}$ É necessária uma atitude de desprendimento de diversos aspectos infantis, e essa necessidade acaba por afetar tanto pais quanto filhos, gerando neles intensos sentimentos de angústia e ambivalência. ${ }^{(3)}$

Rev. Psicol Saúde e Debate. Jan., 2017:2(2):124-145. 
A psicanálise, além de contribuir teoricamente para a construção dessa teoria psicodinâmica da adolescência, diferencia-se de outras abordagens e serve de auxílio ao possibilitar o espaço da fala e da escuta, da construção e desconstrução do indivíduo, permitindo que os sujeitos reconheçam-se em seus devidos papéis, reconciliem-se com seu passado, e possibilitem o reatamento das relações entre pais e filhos, situando cada um desses em seus devidos lugares. ${ }^{(4)}$

Assim sendo, o seguinte artigo tem por objetivo discorrer sob o enfoque psicanalítico alguns aspectos psíquicos que envolvem essa complexa fase da vida, enfatizando os processos de luto pelos quais pais e filhos têm de passar.

\section{METODOLOGIA}

O presente estudo foi efetivado através de uma pesquisa bibliográfica. Utilizou-se para a elaboração desses materiais, tais como: livros adquiridos por meio de compra e empréstimo, artigos retirados de bases de dados (SCIELO e PePSIC), monografias, dissertações retiradas de sites de Instituições de Ensino Superior por meio das seguintes palavras-chave utilizadas: figuras paternas, adolescer, psicanálise.

Foram utilizados materiais publicados no idioma português, preferencialmente no período de 2000 a 2015, além de obras clássicas em psicanálise.

\section{FUNDAMENTAÇÃO TEÓRICA}

\subsection{A VISÃO PSICANALÍTICA DA ADOLESCÊNCIA: um breve histórico}

Sabe-se que - mesmo entre profissionais da área - as expressões puberdade e adolescência ainda são utilizadas indevidamente de acordo com seu contexto, e - por isso torna-se necessário fazer uma distinção entre esses termos diferentes, embora estreitamente relacionados. ${ }^{(1)}$ Puberdade refere-se a um fenômeno biológico que surge a partir de uma atividade hormonal desencadeante dos caracteres sexuais secundários, iniciando-se por volta dos nove anos de idade. Finda-se em torno dos dezoito anos, com a completa maturação e capacidade de fecundação do homem e da mulher, a fim de garantir a perpetuação da espécie

Rev. Psicol Saúde e Debate. Jan., 2017:2(2):124-145. 
humana ${ }^{(2,5)}$ Já a adolescência, é uma transição entre puberdade e estado adulto. É - mais que uma etapa - um processo do desenvolvimento. Por ser um fenômeno social-cultural articulado à constituição do sujeito, pode variar quanto ao aspecto cronológico, tendo seus limites mensurados entre treze e vinte e três anos de idade. ${ }^{(6,7)}$

O fenômeno da adolescência só é encontrado no desenvolvimento do ser humano, e - em termos psicanalíticos - pode ser compreendido como uma reorganização de defesas contra as pulsões sexuais que aparecem em decorrência da puberdade, como uma reedição da separação dos pais ocorrida na infância anteriormente, ou, ainda, como um caminho para alcançar a independência ou busca pela própria identidade. ${ }^{\left({ }^{3}\right)}$ Seguindo o pensamento winnicottiano, a adolescência é um momento em que o jovem busca adaptar-se à realidade, pois seu sentimento é de irrealidade, e sua luta baseia-se em ser alguém e definir seu espaço dentro de um grupo, através de um ambiente firme, seguro e suficientemente bom. ${ }^{(8)}$

Freud pouco usou o termo adolescência em sua obra, apesar de tratar dela em sua maior parte. Porém, é ao se referir ao tema sexualidade, que ele the dá maior ênfase. Utiliza, assim, os termos puberdade ou juventude referindo-se a eles como um momento de definição do sujeito em relação à sua vida sexual, de escolhas objetais definitivas em relação àquelas feitas na infância, e de primazia das zonas genitais. (9) Para ele, a escolha objetal tem uma dimensão incestuosa. Aqui, o jovem desiste das fantasias de incesto e acaba por se desligar de seus progenitores, buscando outros objetos a serem investidos - realizando assim, uma de suas conquistas psíquicas mais importantes e dolorosas. ${ }^{(9)}$ Ele deve romper o apego primário com os objetos iniciais, e levá-lo para outras figuras identificatórias, até que consiga depositá-lo em um objeto heterossexual. ${ }^{(3)}$

Assim sendo, a adolescência, enquanto fase de desenvolvimento, é um momento de verificação da resolução do Édipo, pois nem tudo foi decidido com sua dissolução na infância. Aspectos subjetivos que não puderam ser ligados ou encontrados de significação, voltam numa época mais madura biologicamente, e a estrutura psíquica deve-se abrir ao novo e afastar-se gradativamente dos pais. Tenta-se confirmar o que foi antes estabelecido - a identificação com um genitor - e buscar características do genitor do sexo oposto no parceiro amoroso a que se relacionará. ${ }^{(10)}$ Não é a vivência psíquica que é remodelada, mas sim, o que dela não se conquistou representação, e perdura como algo que não pode ser ligado. O jovem deve realizar a ligação e conquistar a significação para estímulos internos ou externos que Ihe invadem o aparelho mental. ${ }^{(9)}$

Rev. Psicol Saúde e Debate. Jan., 2017:2(2):124-145. 
Freud incumbe as tarefas de busca de autonomia, de desligamento da autoridade dos progenitores, e de ambição aos jovens que passam por essa fase. ${ }^{(9)}$ É importante lembrar que ele postula a sexualidade humana separada em dois tempos, sendo o primeiro relativo a infância (onde a criança vivencia o auto erotismo e o complexo de Édipo, com predomínio das pulsões parciais), e o segundo tempo relativo à puberdade (onde ocorre o despertar da pulsão sexual, incrementada pelas mudanças biológicas, sendo o jovem acometido pela libido de uma nova maneira). ${ }^{(11)}$ Mais do que simplesmente trocar de objetos de investimento, o jovem está lutando por sustentar e manejar seu próprio ego sem a dependência do objeto adulto; ou seja, está lutando por sua própria independência. ${ }^{(3)}$

Anna Freud - primeira psicanalista a tratar da adolescência como tema especifico de investigação - postulava que a sexualidade está presente na vida do sujeito desde seus primeiros anos de vida, e que é na infância que ela toma seus passos mais marcantes. $\mathrm{Na}$ puberdade, porém, surgem inúmeras contradições e instabilidades emocionais, em virtude da maturação dos caracteres sexuais. Tal fato acaba por ocasionar um enorme desequilíbrio no aparelho psíquico, tornando difícil a diferenciação (e sendo esperada tal dificuldade) entre normalidade e patologia. ${ }^{(12)}$ Segundo ela, o que ocorre na adolescência é um incremento da libido sobre o id em decorrência da maturação das funções orgânicas (enquanto que o ego encontra-se fragilizado), e a chave da saúde mental encontrar-se-ia no equilíbrio entre essas forças psíquicas que interagem. É em virtude desse desequilíbrio que é esperada uma normal anormalidade nessa fase da vida. ${ }^{(9)}$

Erik Erikson foi a principal referência no campo da adolescência a partir da década de cinquenta. ${ }^{(9)}$ Ele vivencia uma fase da psicanálise em que a atenção que antes era totalmente voltada para o id, agora volta-se para o ego e seu desenvolvimento (psicologia do ego). Apesar de não romper com a teoria psicossexual de Freud, muda seu enfoque para o problema da identidade e das crises do ego, fornecendo elementos para a compreensão do processo de internalização da cultura no inconsciente individual e na formação da personalidade do ser humano. Segundo ele, tanto a patologia quanto a normalidade deveriam ser entendidas dentro de padrões culturais, ou seja, ambos os conceitos podem mudar conforme a época e a cultura, e se modificam de tempos em tempos. ${ }^{(13)}$

Esse autor considera que o jovem passa por uma revolução fisiológica interior que se soma com as exigências do mundo adulto. Diante dessa revolução, sua principal função é a de buscar seu próprio eu nos outros, afim de conquistar uma identidade una, coesa e própria, que concilie suas obrigações com a vicissitude de sua libido. A adolescência seria, então, uma época de experimentação onde erros por parte do jovem são esperados. ${ }^{(9,14)}$

Rev. Psicol Saúde e Debate. Jan., 2017:2(2):124-145. 
Erikson considera a personalidade como sendo o resultado da interação permanente e simultânea entre as dimensões biológica, social e individual (ego). O ciclo vital, em sua teoria, é dividido em estágios ou crises, e essas não devem ser consideradas como crises catastróficas, mas sim, como eventos necessários: uma oportunidade de mudança e desenvolvimento que precisa ser vivida, suportada e ultrapassada. ${ }^{(9,15)}$

Em cada um desses estágios descritos pelo autor há um conflito a ser superado. Cada um deles subsidia a construção da personalidade relacionando e dando sentido às memórias e experiências vividas num determinado momento (idade) da vida com as experiências vivenciadas nos estágios anteriores. Sua elaboração teórica possui algumas características peculiares, como: o desvio do foco da sexualidade para as relações sociais; o envolvimento de outras etapas do ciclo vital além da infância; a mediação e adaptação entre exigências pessoais e exigências do meio (fazendo ser necessário um maior estudo a respeito da sociedade em que o indivíduo se insere); e em cada estágio o sujeito passa por uma crise que pode ter um desfecho positivo (onde o ego se sobressai mais rico e fortalecido) ou negativo (onde teremos um ego fragilizado). Como característica última a ser apontada, podese dizer que a cada estágio a personalidade se reformula e se adapta a seus sucessos e fracassos. ${ }^{(13)}$

Em Erikson, o conflito relativo ao período da adolescência se define por identidade versus confusão de identidade, e se estabelece, aproximadamente, entre os doze e dezoito anos de idade. Aqui, o encontro e fortalecimento de uma personalidade se dá através das integrações e identificações das identidades até então encontradas pelo jovem. O ego deve conseguir integrar as identificações realizadas em estágios anteriores mais as aptidões naturais da pessoa mais as oportunidades oferecidas pelas funções sociais. A forma como esse ego vivenciou os conflitos de estágios anteriores, como se sobressaiu deles, facilitará ou dificultará esse processo de aquisição de identidade. ${ }^{(13)}$

Quanto a isso, sabe-se que o adolescente entra no mundo (em primeira instância) através de seu corpo, da explosão biológica que lhe acomete. Logo após, entra no mundo através de suas ideias, seus afetos. Para isso, é preciso que se volte para o seu passado, onde o terreno da infância ainda lhe é conhecido e seguro. Necessita reconciliar-se com seu passado para poder situar-se no presente e vislumbrar o futuro. Intelectualiza, elabora para compensar o seu não agir - pois enquanto não se situa, não o consegue. Assim, flutua entre o querer desprender-se e o temor ao desconhecido. O que lhe dará forças para enfrentar tal processo são as vivencias infantis consolidadas em seu mundo interno. A adolescência depende da experiência infantil para lhe tomar a forma que lhe é possível. ${ }^{(7,10)}$

Rev. Psicol Saúde e Debate. Jan., 2017:2(2):124-145. 
Segundo Aberastury e Knobel, a adolescência enquanto fase de desenvolvimento possui um fim, que é identificável à medida que o jovem conquista maturidade biológica, afetiva e intelectual: ${ }^{(7)}$

[...] estará munido de um sistema de valores, de uma ideologia que confronta com a de seu meio e onde a rejeição a determinadas situações cumpre-se numa crítica construtiva. Confronta suas teorias políticas e sociais, e se posiciona, defendendo um ideal. Sua ideia de reforma do mundo se traduz em ação. Tem uma resposta às dificuldades e desordens da vida. Adquire teorias estéticas e éticas. Confronta e soluciona suas ideias sobre a existência ou inexistência de Deus e sua posição não é acompanhada pela exigência de um submeter-se, nem pela necessidade de submeter. ${ }^{(7)}$

Apresenta-se, assim, a visão psicanalítica de adolescência a partir da compreensão de alguns de seus principais teóricos. Entende-se que, segundo eles, essa é uma fase de desenvolvimento do psiquismo que busca integrar exigências do mundo externo com as do próprio mundo interno, e entende-se por seu fim o alcance de diferentes tipos de maturidade. ${ }^{(7)}$

\subsection{A ADOLESCÊNCIA E SEUS PROCESSOS DE LUTO}

A transição da infância para a vida adulta implica em profundas transformações psicológicas, e envolve processos de dúvida e luto (na maioria das vezes inconscientes) que são vividos tanto pelo jovem púbere, quanto por sua família e sociedade. Tal passagem é vista como sendo um momento muito importante, significando uma perda decisiva da condição de criança. É justificável o fato de poderem surgir sentimentos de isolamento e preocupações com a imagem corporal, que podem levar o adolescente a ter atitudes desafiadoras e até mesmo perturbações mentais. ${ }^{(16)}$

Carvajal caracteriza a jornada do adolescente como sendo marcada pela mudança, o temor, a ambivalência e aquisição de novas conquistas. Segundo ele, desde que os pais tenham uma atitude madura frente a saída da posição infantil que até então os filhos ocupavam, a maioria dos jovens lida com a perda dos objetos infantis de forma tranquila. ${ }^{(3)}$

Rev. Psicol Saúde e Debate. Jan., 2017:2(2):124-145. 
Foi a escola argentina criada por Aberastury e Knobel que introduziu o conceito de lutos na adolescência e viu neles o motor da dinâmica adolescente, bem como uma condição fundamental para aceitar novos fatos relacionados à sexualidade, identidade, corpo, pensamento, etc. ${ }^{(3)}$ Esses teóricos afirmam que a aquisição de uma identidade adulta só se dá por completa quando o jovem é capaz de elaborar os lutos próprios dessa fase relativos ao seu corpo, à sua identidade infantil, e aos seus pais da infância. ${ }^{(7)}$

Sobre o luto, o entendemos como sendo o afeto desencadeado pela perda de algo muito importante para o sujeito, bem como sua respectiva elaboração. Freud, em seu texto de 1915 intitulado "Luto e Melancolia", lança as bases para sua compressão psicanalítica, descrevendo processos de identificação, cisão no Eu, bem como a formação de instâncias ideais. Segundo ele, o luto pode ser uma reação a perda de uma pessoa amada ou qualquer abstração que a ela equivalha (como, por exemplo: uma ideia, uma identificação, um estado, e etc.). ${ }^{(4,17)}$

O teste da realidade revelou que o objeto amado não existe mais, passando a exigir que toda a libido seja retirada de suas ligações com aquele objeto. Essa exigência provoca uma oposição compreensível - é fato notório que as pessoas nunca abandonam de bom grado uma posição libidinal, nem mesmo, na realidade, quando um substituto já Ihes acena. [...] São executadas pouco a pouco, com grande dispêndio de tempo e de energia catexial, prolongando-se psiquicamente, nesse meio tempo, a existência do objeto perdido. Cada uma das lembranças e expectativas isoladas através das quais a libido está vinculada ao objeto é evocada e hipercatexizada, e o desligamento da libido se realiza em relação a cada uma delas. [...] É notável que esse penoso desprazer seja aceito por nós como algo natural. Contudo, o fato é que, quando o trabalho do luto se conclui, o ego fica outra vez livre e desinibido. ${ }^{(18)}$

Para que ocorra a elaboração desse processo de luto, o sujeito deve aos poucos desinvestir o ego e encontrar novos objetos aos quais possa investir. Assim, aquele objeto perdido vai aos poucos sendo desinvestido a ponto de apenas ser lembrado com indiferença afetiva. ${ }^{(3)}$

Rev. Psicol Saúde e Debate. Jan., 2017:2(2):124-145. 
O adolescente atravessa esse momento de perdas de forma ativa, e não passiva, pois ao mesmo tempo em que se desprende de um ou outro objeto, ganha outros novos, mais gratificantes e necessários ao seu desenvolvimento. Assim, a perda e o desinvestimento são sempre precedidos de novas conquistas. ${ }^{(3)}$ Sobre tal processo de perdas e ganhos na adolescência, Corso e Corso discorrem belamente:

Há realmente uma perda, perda gradual, não exatamente abrupta, do lugar de objeto de amor dos pais. Ela se dá no momento do desmame, da aquisição da marcha, do controle esfincteriano, da entrada na escola, em suma, é um caminho cheio de estações das quais poderíamos considerar a adolescência como mais uma. Porém, nessa linhagem de perdas, a criança pertence aos pais. É preciso lembrar que, quando chega a adolescência, a infância acabou, o sujeito é parido subjetivamente da família: é expulso do corpo sintomático em cujo ventre se formou. Mas precisa continuar vivendo, ainda é um lactente simbólico. Enfim, podemos dizer que perdeu, mas também ganhou um novo corpo, o mais belo que terá em toda sua vida. Além disso, inaugura-se numa bem vinda distância da sintomatologia dos pais. ${ }^{(5)}$

As transformações da adolescência envolvem, entre outros aspectos, três perdas fundamentais que acabam por desencadear lutos relativos a cada uma dessas: a perda do corpo infantil (pois o jovem precisa adaptar-se e acostumar-se com seu novo corpo), a perda da identidade infantil (pois já não pode mais contar com a proteção que antes era dada por seus pais de infância, e deve acostumar-se com seus novos direitos e obrigações exigidas), e - finalmente - a perda dos pais da infância (onde passa a enxergar seus pais de uma forma mais humana e menos heroicizada - forma a qual, até então, estava acostumado). Para cada uma dessas perdas, gradualmente o processo de luto vai sendo elaborado, desinvestindo a condição passada e dando lugar a uma nova. ${ }^{(19)}$

De forma breve, abordar-se-á a seguir alguns aspectos vivenciados pelo adolescente nos processos de luto pelo seu corpo e sua identidade infantil, e priorizar-se-á a vivência do luto que o acomete quando ele se vê obrigado a desprender-se da imago paterna 
criada por ele até então. Em seguida, discorrer-se-á sobre o luto também vivenciado pelos pais frente ao processo de adolescer de seus filhos.

\subsection{OS LUTOS VIVENCIADOS PELOS ADOLESCENTES}

Relativo ao luto pelo corpo, o jovem angustia-se ao perceber que perde aos poucos seu corpo infantil e que ainda possui uma mente de criança num corpo que aos poucos vai se transformando no de um adulto. ${ }^{(7)}$ Essas mudanças corpóreas o levam a ter de reformular um novo esquema mental a seu respeito. Incapaz de lutar contra tais mudanças, ele desloca sua impotência da esfera da ação para a do pensamento, obtendo um pensamento onipotente (como compensação pela derrota que teve na luta contra as mudanças da realidade)..$^{(7,19)}$ Tudo isso se configura como um processo de elaboração de luto, que se finda quando o adolescente consegue aceitar a perda de seu corpo e bissexualidade infantis (bissexualidade em seu aspecto psicológico: ele deve aceitar que não possui os dois sexos como antes acreditava possuir, e necessita agora do outro para sentir prazer). ${ }^{(7,21)}$ É curioso observar que, em alguns casos, a repressão por parte dos pais ou da sociedade para que o púbere controle seus instintos é tamanha que pode chegar a retardar seu amadurecimento ou desenvolvimento de suas funções sexuais. ${ }^{(19)}$

Quanto ao luto pela identidade infantil, o que ocorre é que, quando criança o sujeito está, naturalmente, como dependente de seus pais. Na adolescência, porém, fica difícil definir um posicionamento concreto (tendo em vista que ele não é mais uma criança, mas também não é um adulto). Cada nova tentativa de desprender-se e independentizar-se é acompanhada por medo e insegurança, e por vezes, retrocessos em posturas infantis. Como saída a esse problema, ele encontra vez nos grupos, onde pode depositar sua confiança e segurança, deixando a responsabilidade e obrigação para os pais. O grupo, aqui, tem função de permitir que o jovem se identifique com outras figuras que não a dos genitores, e acabe por distanciar-se deles (tarefa fundamental a ser realizada), levando-o a construir e reconstruir aos poucos sua personalidade. Ao final, o adolescente poderá ter vivenciado uma multiplicidade de papéis e identificações advindas de diferentes figuras e grupos sociais, até que consiga sintetizar e integrar todas essas, resultando assim em uma identidade una e coesa: a sua identidade. ${ }^{(20,21)}$

Aqui adentrando no que se pretende ser o enfoque dessa sessão de nosso artigo, consequente e simultaneamente ao luto pelo corpo o adolescente vivencia também o luto pelos seus pais de infância. Os pais (que antes eram vistos como heróis e únicos modelos a

Rev. Psicol Saúde e Debate. Jan., 2017:2(2):124-145. 
serem seguidos) agora são percebidos pelos filhos como também sendo seres castrados, como pessoas imperfeitas e não mais donas da razão, impelindo-os em busca de novas identificações. ${ }^{(21)}$ A necessária desestruturação e reestruturação da personalidade é causa de intensa angústia e sofrimento, e visa a restituição do senso de existência e continuidade histórica. ${ }^{(7,22)}$

Vale ressaltar que não se trata de uma morte real dos pais, mas sim, a morte de suas imagos até então cultivadas pelos filhos. Laplanche e Pontalis definem imago como sendo a forma como o indivíduo apreende o outro, e "é elaborado a partir das primeiras relações intersubjetivas reais e fantasmáticas com o meio familiar". Ou seja, imago trata-se de uma representação simbólica inconsciente do que o outro é ou significa para o sujeito, e é nesse sentido que os filhos tem de lidar com a perda dos pais. ${ }^{(23)}$

Apenas quando o jovem soluciona seu processo de luto relativo às imagos parentais é que ele consegue lidar com a questão da escolha sexual. Se o primeiro conflito não é solucionado e vivenciado de forma saudável, suas próximas escolhas objetais serão apenas uma repetição de antigos laços infantis. ${ }^{(24)}$ Freud descreve que é apenas a partir do desligamento com os pais que será possível que o indivíduo adquira conhecimentos e posições diferentes diante da vida. ${ }^{(25)}$ Assim sendo, o adolescente volta-se para o amor heterossexual desviando seu investimento que antes era direcionado totalmente para as figuras parentais, para seu próprio Eu. Os pais - que antes eram supervalorizados - agora devem ser subvalorizados e destituídos desse lugar simbólico. ${ }^{(26)}$

A operação própria da adolescência seria, então, a de lidar com a morte desses pais como suporte do ideal, deixando-os (pais e filhos) frente a frente numa posição de estranhamento um do outro. ${ }^{(4)}$

Observa-se nesse período uma confusão de papéis, pois o jovem busca sua independência, mas ainda não o é. Menospreza as figuras parentais, mas ainda necessita delas pois são tudo o que ele tem até ali. Não pode mais manter a figura dependente da criança infantil, mas também não consegue bastar-se sem ela. Necessita desinvestir os pais que antes foram idealizados, e, para isso, muitas vezes, pode ocorrer um comportamento de hostilidade ou menosprezo frente aos mesmos. A formação de grupos surge como uma tentativa do jovem de buscar identificar-se e ressignificar seu papel e o papel de seus ídolos perante o mundo. As defesas narcísicas (como apegos exagerados a grupos sociais) são respostas à incapacidade de onipotência da criança e dependência dos pais. Os novos 
relacionamentos são uma resposta contra antigas introjeções, bem como tentativas de ressignificá-las. ${ }^{(1,7)}$

Tudo isso ocorre, geralmente, em meio a atitudes rebeldes, contestações, questionamentos, e etc. ${ }^{(26)}$ Os pais, frente a tais oscilações e ambivalências, muitas vezes veem-se incapazes de compreender os filhos, chegando a deixar em suspenso suas funções que deveriam basear-se no apoio e compreensão. ${ }^{(27)}$

Diferenciar-se das expectativas dos pais desperta sentimentos de medo e ameaça no adolescente, e coloca à prova sistemas de estabilidade entre pais e filhos. ${ }^{(28)}$

Por vezes, a agressividade é o componente necessário para que ocorra a desalienação, diferenciação e elaboração de ideais narcísicos, a fim de conquistar uma autonomia. A identidade do adolescente deve ser construída, buscada por ele, e não imposta pela sociedade ou por seus pais. ${ }^{(28)}$

São as primeiras experiências infantis que darão base para que esse jovem atravesse esse caminho de forma saudável ou não. O que foi vivido na infância, retorna na adolescência. Uma criança que cresceu segura e com o apoio dos pais, certamente atravessará a adolescência com mais facilidade que outra que não pôde obter estes requisitos. ${ }^{(29)}$ Alberti reforça essa ideia, pontuando que as relações vivenciadas durante o Complexo de Édipo na infância darão bases para que o jovem se relacione posteriormente em outros momentos de sua vida, fazendo com que ele se volte sempre para a tentativa de apaziguamento do desamparo que o constituiu. ${ }^{(25)}$

Deve-se atentar para o que vem a chamar-se de 'luto patológico por identificação'. Nesse tipo de luto, o que ocorre é uma espécie de cisão no ego do adolescente, que de um lado encontra-se no processo normal do trabalho de luto (desinvestindo ativamente os objetos parentais sem trauma ou sofrimento, mas com temor e ambivalência sendo acrescidos de novas conquistas); e do outro lado está um self que vivencia e se identifica com o sofrimento de seus pais, culpando-se e sentindo-se causa da dor e trauma que os mesmos estão sentindo. Ao ocorrer isso, é grande a possibilidade de que o jovem abra mão de seus próprios ideais e venha a ter uma posição complacente com seus pais, abortando o processo adolescente. $^{(3)}$

\subsection{OS LUTOS VIVENCIADOS PELOS PAIS}

Rev. Psicol Saúde e Debate. Jan., 2017:2(2):124-145. 
Conforme comentado no capítulo anterior, apesar de muito se falar sobre o sofrimento do adolescente em relação às mudanças que lhe acometem, aparentemente são os pais os mais envolvidos nesse processo de luto e busca por adaptação às mudanças próprias dessa fase. ${ }^{(27)}$ Qualquer tentativa de discorrer sobre o tema adolescência que não inclua o árduo e difícil processo de elaboração de luto pelo qual os pais passam, estaria incompleto. É necessário encarar a ambivalência e resistência dos pais em aceitar tal processo de crescimento. ${ }^{(24)}$

A adolescência rompe com a posição de subordinado do filho para com os pais (uma espécie de corte simbólico do cordão umbilical) implicando neles muitas angústias e a revivescência de antigos conflitos. ${ }^{(4)}$ Os adolescentes encontram-se em um estado limite, fazendo apelos. ${ }^{(21)}$ Os pais acabam por perder o corpinho meigo, cheiroso e maleável de seus filhos, bem como seu domínio, subordinação, admiração e obediência. ${ }^{(27)}$ Assim, não deixam de passar por problemas com a elaboração dessa fase. Pais e filhos influenciam-se mutuamente. ${ }^{(20)}$

Os pais ficam numa posição em que necessitam também de entrar em um processo de luto pelo corpo do filho, pela sua identidade de criança, e por sua relação de dependência infantil. São agora julgados por eles, e o desconhecimento acerca de como funciona a mente de um adolescente dificulta ainda mais sua relação pai-filho. ${ }^{(7)}$

\footnotetext{
A adolescência surge como um tempo de construção, que provoca crises de identidade, não somente nos adolescentes, mas também nos pais. Porque os pais já não são mais aqueles pais perfeitos, como os da infância, pois perdem esse lugar que tinham e neste momento se questionam quanto ao seu novo lugar. ${ }^{(28)}$
}

Questões referentes à separação, diferenciação, alteração de lugares e papéis na dinâmica familiar, bem como frustrações advindas do crescer e escolhas feitas pelos filhos, podem ser causa da dificuldade e dos sentimentos de angústia que surgem no trato dos pais com seus filhos adolescentes. O crescimento deles reativa sua própria história, fazendo necessário um novo processo de ressignificação de sua própria adolescência. ${ }^{(28)}$

Rev. Psicol Saúde e Debate. Jan., 2017:2(2):124-145. 
[...] o desejo rebelde da adolescência dos adultos foi reprimido, ou seja, preferiram esquecê-los para não realizá-los. No entanto os adolescentes transgridem o que os adultos têm vontade de explicitar. O fato é que a adolescência é uma interpretação de sonhos adultos, produzida por uma moratória que força o adolescente a tentar descobrir o que os adultos querem [...]. Os adolescentes de hoje convidam os pais para observarem enquanto pessoas, para que vejam o que fizeram com suas vidas. Talvez estes pais passaram sua adolescência sem crise, então agora pais e filhos passam juntos esta crise. De certo modo os pais revivem seus próprios fatos recalcados, agora na adolescência do filho. ${ }^{(28)}$

O que ocorre é que - numa sociedade repressora como a em que vivemos atualmente - pais e adultos pouco tiveram oportunidades de falar, elaborar ou vivenciar livremente sua própria adolescência, e ao defrontarem-se com seus filhos agora nessa condição ou portam-se como eles ou negam a ocorrência do fenômeno. ${ }^{(4)}$ Assim, a forma como esses pais vivenciaram sua própria adolescência vai influenciar esse novo tempo de atualização. (21) Pais que viveram uma adolescência angustiante e que não tiveram tempo ou espaço para elaborá-la, ao defrontarem-se com a adolescência de seus filhos são convidados a reviver seus conflitos, e têm perante eles dois tipos de atitude: ou regridem e passam a manter uma postura adolescente (invadindo o espaço de seu filho e fazendo-lhe sentir-se ameaçado), ou assumem uma postura autoritária, violenta e manipuladora (gerando sentimentos de angústia e revolta nos filhos, podendo fazer surgir daí atitudes extremas de confronto - como o suicídio, por exemplo). ${ }^{(3)}$

Os filhos agora aparecem como sendo estranhos aos pais e à família. Os pais não reconhecem no filho os frutos de seus melhores esforços, e o adolescente não quer se reconhecer nos pais, pois vive em busca de novas identificações alheias às que têm dentro de casa. Tal estranhamento não possui caráter patológico, mas sim, faz parte da dinâmica de desprendimento entre ambos. ${ }^{(4)}$

Os pais podem vir a ficar confusos com as atitudes de desdenho, ambivalência e desprezo de seus filhos, e se acharem desnecessários ou descartáveis (já que os filhos recusam-se a ouvi-los). ${ }^{(26)}$ Mas é necessário esclarecer que tal desdenho e desprezo configura-se como uma defesa frente ao difícil processo de desprendimento das partes 
infantis, e deve ser visto como um juízo de valor que deve ser respeitado. Os pais, na maioria das vezes, não conseguem entender tal dinâmica, e colocam-se numa posição de ressentimento e reforço da autoridade. ${ }^{(7)}$ Assim sendo, necessitam de um afastamento em relação aos filhos a fim de reconhecer neles as transformações próprias dessa fase. ${ }^{(28)}$

Vale pontuar que o corpo do púbere pode refletir como um espelho das posições edipianas parentais, e o afastamento por parte dos pais implica que eles aceitem sua condição de obsoletos, de rejeição e inadequação frente à nova fase na vida do filho. ${ }^{(30)}$ Muitos pais projetam em seus filhos seus próprios desejos edipianos, sexualizando todas as cenas vividas por eles, estando o tempo todo desconfiados e criando-Ihes situações embaraçosas. ${ }^{(28)}$

Há um tipo de estranhamento característico relativo ao corpo dos adolescentes: os pais veem nos filhos um corpo diferente daqueles que estavam acostumados; mas este não é o corpo dos filhos, e sim, seu próprio corpo - seu corpo adolescente - que outrora teve e que hoje the põe de frente com temas como velhice e morte. $O$ adulto grita seu descontentamento com a nova imagem. A imagem que não reconhece não é a de seu filho, mas antes, sua própria imagem. ${ }^{(4)}$

Podem ocorrer, então, sentimentos de inveja nos adultos, seja pelos corpos esbeltos e belos de seus filhos, ou seja pela sua criatividade, originalidade, enfrentamento e liberdade. Tal inveja, quando negada, pode refletir no comportamento mimetizado dos pais com os filhos, que sob a desculpa da amizade acabam por se comportar quase que ridiculamente como os filhos adolescentes. Quanto a esse caráter de amizade, deve ficar claro que não devemos ser amigos de nossos filhos: devemos sim, ser pais. Essa distância normal e natural é bem vinda aos jovens. ${ }^{(3)}$

Nesse momento, pais (agora desinvestidos e deixados de lado) devem abandonar a própria imagem idealizada que tinham de si mesmo, que seu filho criou e na qual ele mesmo se acomodou. Não será mais seu líder ou ídolo, e deverá adaptar-se a uma nova relação cheia de críticas e conflitos. Consequentemente, deverá saber avaliar suas qualidades e defeitos, fazendo um balanço de como tem vivido não apenas seu papel de pai, mas de pessoa como um todo. Apenas identificando-se com a força criativa do filho é que será capaz de compreendê-lo e aceitá-lo. ${ }^{(7)}$.

Assim, frente a tal estranhamento, os pais têm duas saídas: ou decretam seu permanente estado de horror excluindo-se de cena, ou retornam à sua própria posição de adolescentes, passando a agir como os filhos e inviabilizando a possibilidade de que eles o tenham como figura identificatória, deixando-os num completo desamparo. ${ }^{(26)}$

Rev. Psicol Saúde e Debate. Jan., 2017:2(2):124-145. 
Com a emergência da genitalidade e livre manifestação de personalidade que dela surge, os pais comumente têm uma atitude de liberdade excessiva, consentindo a todas as vontades do púbere. Isto pode também ser percebido por ele como um abandono, e que o é na verdade. ${ }^{(7)}$ Possivelmente as perturbações narcísicas dos adolescentes se devem à falta de sustentação e estabilidade no contato com os adultos, produtos de suas identificações. ${ }^{(26)}$

Existem casos em que o processo de desprendimento dos filhos com os pais é vivenciado com tanto sofrimento, que os pais recusam-se a deixar os filhos desprenderemse. Se deprimem, se angustiam e usam o discurso dos perigos e riscos provenientes da vida para impedir que o filho se lance ao mundo como assim deveria fazê-lo, mantendo-o numa eterna posição infantil. ${ }^{(29)}$

Os pais precisam saber que na adolescência precoce moças e rapazes passam por um período de profunda dependência, onde precisam tanto ou mais do que quando eram bebês, que essa necessidade de dependência pode ser seguida imediatamente de uma necessidade de independência, que a posição útil nos pais é de espectadores ativos, não passivos, e ao ceder à dependência ou à independência não se baseiam em seus estados de ânimo, mas nas necessidades do filho. Para isto será necessário que eles mesmos possam ir vivendo o desprendimento do filho, concedendo-lhe a liberdade e manutenção da dependência madura. ${ }^{(7)}$

Tal atitude de desprendimento pode tornar-se mais dificultosa ainda quando os filhos são a única fonte de gratificação desses pais. Pais com empregos ou casamentos frustrados, que fazem de seus filhos sua única razão de viver, certamente encontrarão mais dificuldade para atravessar essa fase. A dependência e sensação de controle onipotente do adulto em relação à criança criam falsas sensações de segurança e importância no adulto (muitas vezes as únicas que obtém em seu meio). O que mais dói perder, no entanto, são os processos de idealização extrema que a criança faz de seus pais. ${ }^{(3)}$

Para o jovem, não é fácil que - além de carregar as angústias próprias desta fase - tenha de lidar com o peso das expectativas e exigências do adulto oriundas de suas mal sucedidas elaborações. ${ }^{(28)}$ A autonomia e distanciamento do adolescente em relação aos pais 
são características muito necessárias do processo, que devem ser guiadas pelos mesmos, sendo eles os responsáveis por fornecer suporte e continente. Devem, assim, diferenciar-se dos filhos abrindo mão de suas próprias satisfações pulsionais para que os filhos se reconheçam como diferentes e saibam situar seu próprio lugar no mundo. ${ }^{(30)}$

É necessário reinventar o lugar ocupado pelos pais, de forma que eles vivenciem e elaborem o luto que lhes cabe. Ser pai ou mãe de uma criança é diferente de ser pai ou mãe de um adolescente, e requer um reposicionamento de razões tanto sociais quanto pessoais. Os pais - assim como os filhos - devem agora buscar novas possibilidades de investimento libidinal, de forma a separarem-se parcialmente um do outro. É necessário que assumam-se como os adultos de seu tempo, e enfrentem de forma direta certas verdades inescapáveis (como a iminência da velhice e da morte) fazendo, assim, uma reconstrução simbólica de si mesmos. ${ }^{(28)}$

O papel da comunicação entre pais e filhos neste momento é de fundamental importância. Ela deve, preferivelmente, ter suas raízes fincadas desde a infância (pois como bem dito, é a qualidade dos laços antes criados que dará suporte para uma saudável resolução dos conflitos da adolescência). Há comunicação desde que haja troca de significação. Para haver comunicação não basta que a mensagem seja expressa, mas sim, que ela seja entendida. ${ }^{(24)}$

Por fim, a possível saída para a resolução desses impasses e conflitos entre pais e filhos durante a adolescência seria a de um reatamento entre ambos (aspecto no qual a psicanálise mostra-se como sendo de muita serventia), re-historicizando esses sujeitos, permitindo que ambos voltem a reconhecer-se em seus devidos papéis, e que thes seja permitido falar de experiências e vivências passadas, a fim de situarem-se no momento presente. $^{(4)}$

\section{CONCLUSÃO}

A adolescência é um conceito no qual podem ser trabalhadas diversas vertentes, tomando por base aspectos biológicos, psicológicos e/ou sociais. No referido trabalho aqui apresentado, enfatizou-se o aspecto psicológico, utilizando-se o viés psicanalítico.

Rev. Psicol Saúde e Debate. Jan., 2017:2(2):124-145. 
Psicanalistas contemporâneos vêm complementar o estudo a respeito da adolescência referindo-se a ela ora como sendo um período de desequilíbrio psíquico, ora como uma crise normativa, e ora como uma síndrome normal.

Aberastury e Knobel introduzem o conceito de luto na adolescência, e veem em sua elaboração o motor da dinâmica mental necessária para o alcance de uma identidade adulta e madura. São elucidados três tipos de luto pelos quais o adolescente perpassa: o luto pelo seu corpo infantil, pela sua identidade infantil, e por seus pais de infância. A vivência de tais lutos gera uma pluralidade de sentimentos na mente tanto do adolescente quanto das pessoas que com ele convivem.

Os pais - confusos frente ao novo que lhes apresenta - também necessitam elaborar o luto advindo da perda de seu filho enquanto criança, de sua relação de dependência e subordinação; bem como devem aceitar o fato de que não são mais os ídolos que seus filhos tanto admiravam. Para isso, devem distanciar-se (porém, não se anularem), e permitirem que pais e filhos reconheçam-se em seus devidos lugares e papéis, dando o suporte necessário para que os filhos consigam desprenderem-se e conquistarem mais que uma identidade, mas sim, seu lugar enquanto sujeito no mundo.

Ao fim desse trabalho, acredito que a pesquisa tenha conseguido alcançar seu objetivo de discorrer sobre os aspectos psíquicos que perpassam a mente de um jovem adolescente, bem como o de elucidar os processos de luto que acometem a ele e também a seus pais.

O pensar adolescente é repleto de características peculiares e confusas que justificam suas atitudes de rebeldia, enfrentamento ou isolamento frente ao mundo. A maior parte dessas características está ligada ao processo de desprendimento necessário que esses jovens têm de realizar em relação a seus pais. Assim, acabam por menosprezá-los, julgando não precisar deles, e buscando nos grupos ou outras figuras de identificação a segurança necessária para esse solitário momento. Tal atitude mostra-se como sendo uma tentativa e necessidade de provarem que já não são mais dependentes, e que possuem sua própria singularidade, sendo alguém no mundo, apesar de agora estarem separados das figuras primais.

Frente a essa perigosa (porém necessária) busca por autonomia e identidade do adolescente, os pais são os responsáveis por lhe fornecerem continente, base e sustentação para que atravessem essa difícil fase da vida. Atitudes que constroem tal base devem iniciarse logo no início da criação desses filhos, através da boa comunicação, diálogo, e uma certa

Rev. Psicol Saúde e Debate. Jan., 2017:2(2):124-145. 
dose de liberdade. Essa construção, porém, prolonga-se por toda a vida, exigindo dos pais que se permitam conhecerem-se, repensando suas vivencias passadas enquanto adolescentes, assumindo verdades que nem sempre lhes agradam, e permitindo - assim que se situem no momento presente e resinifiquem seus lugares enquanto pais e sujeitos. Ao fazerem isso, estarão diferenciando-se da postura imatura e confusa que os adolescentes apresentam, e permitindo que eles vejam neles uma identificação saudável relativa ao que é ser um adulto.

A adolescência é um complexo processo de desabrochar pelo qual todos nós passamos, e acredito que entendê-la possa significar propiciar a esses jovens que hoje nos rodeiam uma travessia mais segura, compreensiva e de caráter menos traumático. Como consequência, poderíamos ao final ter - assim - adultos responsáveis, esclarecidos e ativos em seus devidos papéis sociais. Reconheço, porém, que esse é um tema extenso que não nos possibilitaria ser tratado aqui em sua forma integral, e convido os interessados a aprofundarem seus estudos em obras clássicas de autores anteriormente aqui citados, como Erikson, Aberastury e Knobel, Outeiral, entre outros.

\section{REFERÊNCIAS}

1 Outeiral J. Adolescer. 3aㅡ ed. Rio de Janeiro: Revinter; 2008.

2 Pratta EMM, Santos MA. Família e adolescência: a influência do contexto familiar no desenvolvimento psicológico de seus membros. Psic em est. 2007;12(2):247-56.

3 Carvajal G. Tornar-se adolescente: a aventura de uma metamorfose. $2^{\underline{a}}$ ed. São Paulo: Cortez; 2001.

4 Corso M, Corso D. Game over. In: APPOA. Adolescência entre o passado e o futuro. Porto Alegre: Artes e Ofícios; 1999. pp. 81-95.

5 Einsenstein E. Adolescência: definições, conceitos e critérios. Adol e saúde. 2005;2(2):6-7. 
6 Sadala G, Garritano EJ. Adolescência e contemporaneidade. Com de pesq. revista Trivium: estudos interdisciplinares ciência, tecnologia e religião. 2010;2(2):340-45.

7 Aberastury A, Knobel M. Adolescência normal. 5ae ed. Porto Alegre: Artes Médicas; 1986.

8 Oliveira DM, Fulgencio LP. Contribuições para o estudo da adolescência sob a ótica de Winnicott para a educação. Psic em rev. 2010;16(1):64-80.

9 Matheus TC. Adolescência: clínica psicanalítica. São Paulo: Casa Psi Livraria; 2007.

10 Domingues MRC, Domingues TLC, Baracat J. Uma leitura psicanalítica da adolescência: mudança e definição. Rev cien elet psic. 2009;2(12).

11 Viola DTD, Vorcaro AMR. O problema do saber na adolescência e o real na puberdade. Psic USP. 2015;26(1):62-70.

12 Avila SFO. A adolescência como ideal social. In: Anais do I Simpósio Internacional do Adolescente, 1., [internet]; maio 2005; Rio de Janeiro, Brasil. [acesso em 23 ago. 2016]. São Paulo: Faculdade de Educação da Universidade de São Paulo; 2005. Disponível em: http://www.proceedings.scielo.br/scielo.php?script=sci_arttext\&pid=MSC0000000082005000 200008\&lng=en\&nrm=iso

13 Carpigiani B. Erik H. Erikson: teoria do desenvolvimento psicossocial. Carpsi Serv Psic Sau Gest. 2010;7:1-21.

14 Silva TC, Mendes DF. A contemporaneidade acerca da adolescência e a sexualidade. Psico Saud Deb. 2015;1(1):1-18.

15 Suaréz AS. Crise de identidade na adolescência: breve análise e implicações para a práxis religiosa segundo a teoria de Erik Erikson. Acta Cien - Cien Hum. 2005;2(9):31-8.

16 Anjos SCBDG. Desesperança e agressividade na adolescência e qualidade de vinculação aos pais. [Dissertação]. Lisboa: Universidade Lusófona de Humanidades e Tecnologias; 2010.

Rev. Psicol Saúde e Debate. Jan., 2017:2(2):124-145. 
17 Tanis B. Especificidade no processo de elaboração do luto na adolescência. Rev. Bras Psic. 2009;43(3):39-50.

18 Freud S. Luto e melancolia. In: Freud S. A história do movimento psicanalítico, artigos sobre metapsicologia e outros trabalhos. Rio de Janeiro: Imago; 1996. p.245-263.

19 Neiva KMC, Abreu MM, Ribas TP. Adolescência: facilitando a aceitação do novo esquema corporal e das novas formas de pensamento. Rev psic vet ed. 2004;5(2):56-4.

20 Garritano EJ, Sadala G. O adolescente e a cultura do corpo: uma visão psicanalítica. Lab Est Con Pol. 2010;9(3):56-64.

21 IJ Sena, MLSO Farias. Função paterna e adolescência em suas relações com a violência escolar. Rev mal est subj. 2010;10(1):117-136.

22 Stevanato I, Romeu LC. Psicoterapia breve psicodinâmica com adolescente após alta. psiquiátrica: Estudo de caso. In: In: Anais do I Simpósio Internacional do Adolescente, 1., [internet]; maio 2005; Rio de Janeiro, Brasil. [acesso em 09 set.. 2016]. São Paulo: Faculdade de Educação da Universidade de São Paulo; 2005. Disponível em: http://www.proceedings.scielo.br/scielo.php?script=sci_arttext\&pid=MSC0000000082005000 200079\&lng=en\&nrm=abn

23 Laplanche J, Pontalis JB. Vocabulário de psicanálise. 7ª̣ ed. São Paulo: Martins Fontes; 1983. p. 305.

24 Fabião E. Adolescentes, pares e família. Que cumplicidades?. Acta Pediatr. 1998;29(1):3542.

25 Ferrão VS, Poli MC. Adolescência como tempo do sujeito na psicanálise. Adolesc Sau. 2014;11(2):48-55.

26 Macedo MMK, Falcão CNB. A escuta na psicanálise e a psicanálise da escuta. Psychê. 2005;15(9):65-76.

Rev. Psicol Saúde e Debate. Jan., 2017:2(2):124-145. 
27 Mohr MA, Valore LA. Rebeldia adolescente: um olhar à luz das contribuições da psicanálise. Psicodom. 2009;1(4):1-18.

28 Rotili ALD. O adolescente e os vínculos familiares [Monografia]. Ijui: Universidade Regional do Noroeste do Estado do Rio Grande do Sul-UNIJUÍ; 2012.

29 Campos DMS. Psicologia da adolescência: normalidade e psicopatologia. 19a ed. Petrópolis: Vozes; 2002.

30 Kernier N, Cupa D. Adolescência: muda psíquica à procura de continentes. Ágora. 2012;(15):453-467. 